\title{
Alveolar Bone Dimensions of Mandibular Posterior Teeth using Cone Beam Computed Tomography: A Pilot Study
}

\author{
${ }_{1}^{1}$ Varun Rajeev Kunte, ${ }^{2}$ Ajay Ramesh Bhoosreddy, ${ }^{3}$ Seema Ajay Bhoosreddy, ${ }^{4}$ Atul Ashok Pandharbale \\ ${ }^{5}$ Manila Rajaram Shinde, ${ }^{6}$ Bhushan Sukhdeo Ahire
}

\begin{abstract}
Aim: The aim of this study was to analyze bone dimensions of the dentate posterior mandible using cone beam computed tomography (CBCT).

Objectives: The objectives of this study were

- To measure thickness of buccal and lingual bone walls in mandibular posterior teeth using CBCT.

- To measure alveolar bone width in mandibular posterior teeth using CBCT.
\end{abstract}

Materials and methods: Ten CBCT scans were included in the study ( $n=65$ teeth). Thicknesses of buccal and lingual walls were measured at measurement point 1 (MP1) and measurement point 2 (MP2). Alveolar width was assessed at most coronal detected alveolar bone (BW1) and at superior border of mandibular canal (BW2). Vertical distance between BW1 and BW2 was measured $(\mathrm{H})$. Data were tabulated and results were statistically analyzed using unpaired t test.

Results: The study showed that there was an increase in bone wall thickness from 1st premolar to 2 nd molar for buccal and lingual alveolar plates. Lingual bone walls were thicker than buccal bone walls at MP1 and MP2 for all teeth. Bone width for premolars was considerably less than bone width of molars.

Conclusion: Careful preoperative analysis using CBCT is important to assess need of bone augmentation procedures. As the bone thickness and width in the molar region is more adequate, prognosis of implants placed in molar region may be better.

Clinical significance: Analysis of bone dimensions is of utmost importance for successful outcome of bone augmentation procedures in implant treatment.

Keywords: Alveolar bone dimensions, CBCT, Implants Mandibular posterior teeth.

How to cite this article: Kunte VR, Bhoosreddy $A R$, Bhoosreddy SA, Pandharbale AA, Shinde MR, Ahire BS. Alveolar Bone Dimensions of Mandibular Posterior Teeth using Cone Beam Computed Tomography: A Pilot Study. J Contemp Dent 2016;6(1):9-14.

\footnotetext{
${ }^{1,4-6}$ Postgraduate Student, ${ }^{2}$ Professor and Head, ${ }^{3}$ Professor

1,2,4-6 Department of Oral Medicine and Radiology, MGV's KBH Dental College and Hospital, Nashik, Maharashtra, India

${ }^{3}$ Department of Oral and Maxillofacial Surgery, MGV's KBH Dental College and Hospital, Nashik, Maharashtra, India

Corresponding Author: Varun Rajeev Kunte, Postgraduate Student, Department of Oral Medicine and Radiology, MGV's KBH Dental College and Hospital, Nashik, Maharashtra, India Phone: +919833299986, e-mail: drvarunkunte@gmail.com
}

\section{Source of support: Nil \\ Conflict of interest: None}

\section{INTRODUCTION}

Implant treatment is a common procedure in dental practice. Immediate or early placement approach increases the attractiveness of implant therapy. After extraction, the alveolar process undergoes marked alterations because of which alveolar bone width and height of buccal bone changes significantly. Postextraction implant sites often require bone augmentation procedures to achieve and maintain successful osseointegration. Alveolar bone dimensions prior to extraction may be an important determinant of bone morphological changes that occur postextraction. Analysis of the dimensions may be important in formulating appropriate treatment plan. ${ }^{1}$ Additionally, placement of immediate implants in fresh extraction sockets could prevent osseous changes that occur postextraction. ${ }^{2}$ Clinical observations suggest that buccal bone resorption varies in magnitude among individuals and from site to site. Factors that affect this include the presence and absence of an infection, flap vs flapless extraction, traumatic extraction, and buccal bone wall thickness. ${ }^{3}$ There is lingual bone concavity in mandibular posterior region owing to submandibular gland fossa. Dental implants in the region, if not placed properly, can perforate the lingual bone or damage the lingual nerve leading to treatment failure. ${ }^{1}$

Cone beam computed tomography (CBCT) is a promising diagnostic and prognostic tool in the implant therapy. It provides high resolution images of oral and maxillofacial region with lower radiation dose than conventional computed tomography. ${ }^{1,4}$ It provides the clinician with third dimension that makes it better than two-dimensional imaging modalities such as intraoral periapical radiographs, orthopantomographs, etc. ${ }^{5}$ Hence, it is imperative to evaluate bone dimensions of mandibular posterior teeth, such as buccal and lingual bone plate thickness, alveolar bone width, and distance from the inferior alveolar canal using CBCT. The aim of this study was to evaluate thickness of buccal and lingual bone walls and width of the alveolus in patients undergoing implant therapy. 


\section{MATERIALS AND METHODS}

This study included all the CBCT scans of patients who were referred for implant therapy to the Department of Oral Medicine and Radiology, MGV's KBH Dental College and Hospital, Nashik, Maharashtra, India. Clearance of the Institutional Ethical Committee was taken. Machine used was SIRONA ORTHOPHOS XG 3D, Germany. Software used was Galileos viewer.

A total of 10 CBCT scans of which 65 teeth were included in the sample size. Data were reconstructed with slices of $1 \mathrm{~mm}$ thickness. Slice location passed through center of respective tooth parallel to the long axis of root that dictated vertical orientation of slice. Mesial and distal roots having different axes were analyzed differently.

Teeth having periapical pathologies, which are indicated for apical surgery, were excluded from the study owing to the possible effects of periapical pathologies on alveolar bone dimensions at the analyzed sites. Patients with systemic diseases were excluded from the study. All other teeth were analyzed irrespective of their present pathology. Due to varying anatomy, third molars were not considered in the study.

Measurements were taken on cross-sectional view, which showed complete root and cementoenamel junction (CEJ). Thicknesses of buccal and lingual walls were measured on two locations on teeth, $4 \mathrm{~mm}$ apical to CEJ (MP1) and at the middle of the root (MP2) as shown in Figure 1. Alveolar crest width was measured at the most coronally detected buccal bone (BW1) and at the superior border of inferior alveolar canal (BW2). Vertical distance between BW1 and BW2 is measured as height $(\mathrm{H})$ as depicted in Figure 2. Data were tabulated and analyzed

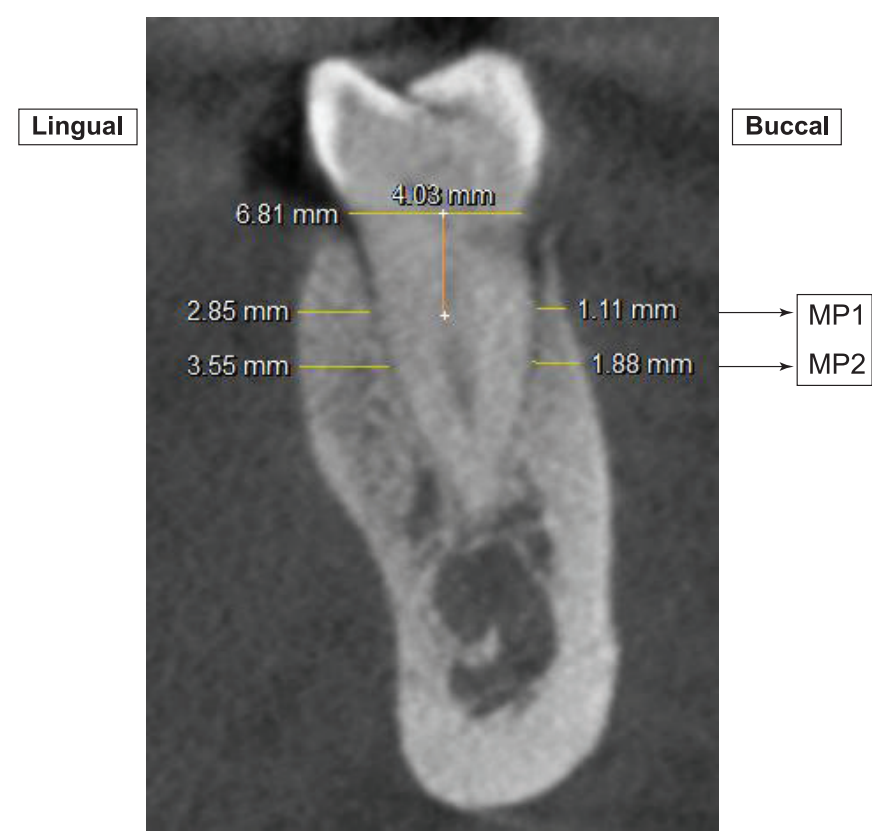

Fig. 1: Measurement of buccal and lingual bone wall thickness at MP1 and MP2

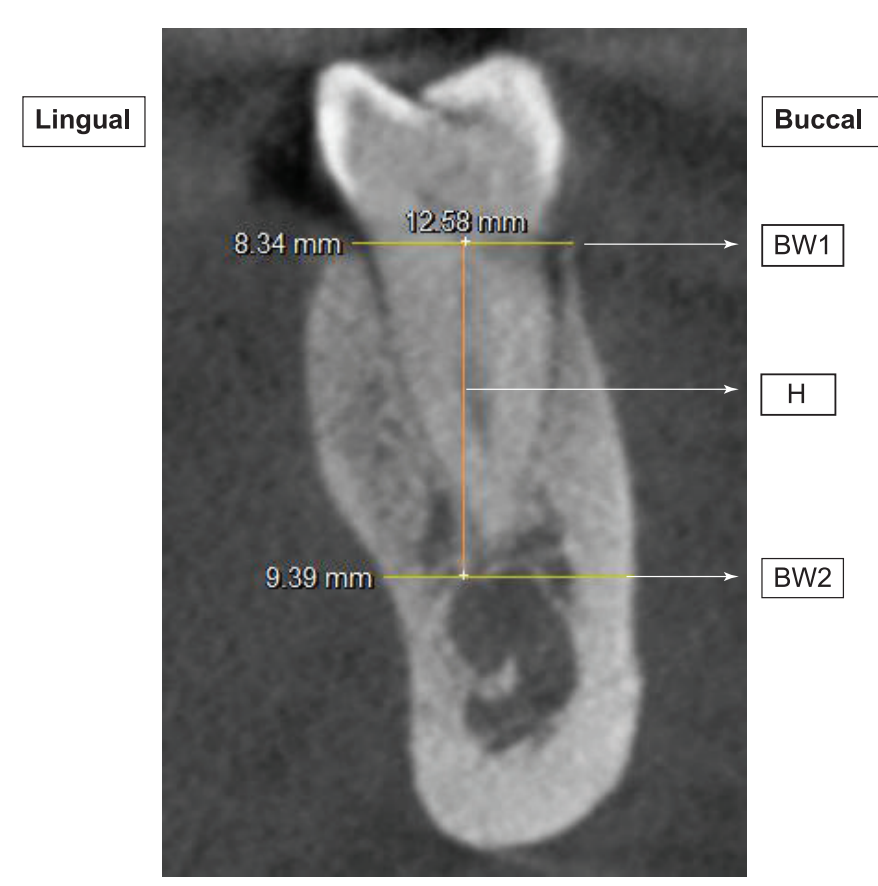

Fig. 2: Measurement of height $(\mathrm{H})$ and bone width (BW1 and BW2)

in Microsoft Excel. Minimum and maximum values for bone thickness and bone width were calculated. Median and mean was also calculated for the same. Unpaired $t$ test at $95 \%$ confidence intervals and two-tailed was used.

\section{RESULTS}

Total sample size was 65 teeth. Distribution of teeth analyzed is depicted in Table 1.

Results of the study show that there was a gradual increase in bone wall thickness from 1st premolar to 2nd molar. At MP1, the range of mean value of buccal bone wall thickness was 0.431 to $1.786 \mathrm{~mm}$ from 1st premolar and 2nd molar respectively, as summarized in Table 2. At MP2, the range of mean value of buccal bone wall thickness was 0.862 to $3.63 \mathrm{~mm}$ from 1st premolar to 2nd molar respectively, as summarized in Table 3. Lingual bone wall thickness was considerably higher than buccal bone wall thickness at both MP1 and MP2. This difference was statistically significant for all teeth at MP1 as summarized in Table 4. It also shows a steady increase from a mean value of 1.611 to $2.86 \mathrm{~mm}$ at MP1 from 1st premolar to 2nd molar respectively. At MP2, lingual bone thickness values increased from 2.951 to $3.835 \mathrm{~mm}$ from 1st premolar to 2nd molar respectively. With exception of 2nd molar, difference between buccal and lingual bone walls at MP2 was statistically significant for all teeth as summarized in Table 5.

Table 1: Distribution of teeth analyzed

\begin{tabular}{lllll}
\hline PM1 & $P M 2$ & M1 & M2 & Total \\
\hline 17 & 18 & 14 & 16 & 65 \\
\hline
\end{tabular}

PM1: 1st premolar, PM2: 2nd premolar, M1: 1st molar, M2: 2nd molar 
Alveolar Bone Dimensions of Mandibular Posterior Teeth

Table 2: Thickness of buccal and lingual bone plates

\begin{tabular}{llllll}
\hline & & $\begin{array}{l}\text { Minimum } \\
(\mathrm{mm})\end{array}$ & $\begin{array}{l}\text { Median } \\
(\mathrm{mm})\end{array}$ & $\begin{array}{l}\text { Maximum } \\
(\mathrm{mm})\end{array}$ & $\begin{array}{l}\text { Mean } \\
(\mathrm{mm})\end{array}$ \\
\hline PM1 & Buccal & 0 & 0.25 & 1.37 & 0.431 \\
& Lingual & 0 & 1.49 & 3.36 & 1.611 \\
PM2 & Buccal & 0 & 0.5 & 1.37 & 0.437 \\
& Lingual & 0.74 & 1.87 & 3.47 & 1.976 \\
M1M & Buccal & 0.35 & 0.81 & 2.36 & 0.965 \\
& Lingual & 0.74 & 2.05 & 3.87 & 2.02 \\
M1D & Buccal & 0 & 0.775 & 1.63 & 0.73 \\
& Lingual & 1.36 & 2.615 & 3.36 & 2.411 \\
M2M & Buccal & 0 & 1.25 & 2.85 & 1.395 \\
& Lingual & 0.88 & 1.865 & 5.59 & 2.148 \\
M2D & Buccal & 0 & 1.19 & 4.83 & 1.786 \\
& Lingual & 1.12 & 2.68 & 5.59 & 2.86
\end{tabular}

AT MP1, PM1: 1st premolar, PM2: 2nd premolar, M1M: Mesial root of 1st molar, M1D: distal root of 1st molar, M2M: Mesial root of $2 \mathrm{nd}$ molar, M2D: distal root of 2nd molar

Table 4: Dimensions of buccal and lingual bone walls of all teeth at MP1 $(p<0.05$ significant)

\begin{tabular}{lllr}
\hline MP1 & $\begin{array}{l}\text { Buccal (mean } \\
\pm S D)(\mathrm{mm})\end{array}$ & $\begin{array}{l}\text { Lingual }(\text { mean } \\
\pm S D)(\mathrm{mm})\end{array}$ & \multicolumn{1}{c}{$p$-value } \\
\hline PM1 & $0.43 \pm 0.48$ & $1.61 \pm 0.96$ & $<0.0001$ \\
PM2 & $0.44 \pm 0.38$ & $1.98 \pm 0.82$ & $<0.0001$ \\
M1M & $0.87 \pm 0.61$ & $1.95 \pm 0.82$ & 0.0001 \\
M1D & $0.74 \pm 0.63$ & $2.41 \pm 0.71$ & $<0.0001$ \\
M2M & $1.40 \pm 0.91$ & $2.15 \pm 1.13$ & 0.0467 \\
M2D & $1.79 \pm 1.51$ & $2.86 \pm 1.23$ & 0.0349 \\
\hline
\end{tabular}

SD: Standard deviation

About $88.23 \%$ of 1 st premolars and $88.89 \%$ of 2 nd premolars showed very thin or no buccal bone wall (less than $1 \mathrm{~mm}$ ) at MP1. About $41.17 \%$ of 1 st premolars and $50 \%$ of 2 nd premolars had lingual bone wall between 1 and $2 \mathrm{~mm}$. About $29.41 \%$ of 1 st premolars and $11.11 \%$ of 2nd premolars had lingual bone wall less than $1 \mathrm{~mm}$ at MP1, as depicted in Table 6 . About $64.28 \%$ of 1 st molars too had a buccal bone wall less than $1 \mathrm{~mm}$ at MP1 as shown in Graph 1 and Table 6. At MP2, 64.7\% 1st premolars had thin or missing buccal bone walls. However, $93.75 \%$ of 2nd molars showed thicker lingual bone walls of more than $2 \mathrm{~mm}$ as shown in Graph 2 and Table 6.

At the most coronally detectable alveolar bone BW1, mean bone width was 7.75 to $7.64 \mathrm{~mm}$ for premolars and 9.64 to $9.47 \mathrm{~mm}$ for molars. At BW2, bone width was 10.95 to $10.83 \mathrm{~mm}$ for premolars and 11.07 to $11.36 \mathrm{~mm}$ for molars. There was presence of lingual undercut that increased from 1st premolar to 2nd molar. Bone width values were considerably higher in molars than in premolars. Also, bone width increased from BW1 to BW2 as summarized in Table 7 and Graph 3. Difference between BW1 and BW2 is statistically significant for all teeth. BW1 values were considerably thinner than BW2 as summarized in Table 8. Vertical distance between BW1
Table 3: Thickness of buccal and lingual bone plates at MP2

\begin{tabular}{llllll}
\hline & & $\begin{array}{l}\text { Minimum } \\
(\mathrm{mm})\end{array}$ & $\begin{array}{l}\text { Median } \\
(\mathrm{mm})\end{array}$ & $\begin{array}{l}\text { Maximum } \\
(\mathrm{mm})\end{array}$ & $\begin{array}{l}\text { Mean } \\
(\mathrm{mm})\end{array}$ \\
\hline PM1 & Buccal & 0 & 0.88 & 2.6 & 0.862 \\
& Lingual & 1.63 & 2.87 & 4.83 & 2.951 \\
PM2 & Buccal & 0.37 & 1.125 & 3.47 & 1.373 \\
& Lingual & 0.87 & 2.98 & 4.35 & 3.001 \\
M1M & Buccal & 0.28 & 1.15 & 2.72 & 1.251 \\
& Lingual & 1.86 & 2.87 & 4.01 & 2.895 \\
M1D & Buccal & 0.51 & 1.305 & 2.6 & 1.451 \\
& Lingual & 2.66 & 3.855 & 5.59 & 3.94 \\
M2M & Buccal & 0.63 & 3.23 & 6.59 & 3.051 \\
& Lingual & 1.99 & 3.28 & 6.46 & 3.367 \\
M2D & Buccal & 1.14 & 3.23 & 7.34 & 3.63 \\
& Lingual & 2.23 & 3.635 & 6.46 & 3.835
\end{tabular}

Table 5: Dimensions of buccal and lingual bone walls of all teeth at MP2 ( $p<0.05$ significant $)$

\begin{tabular}{llll}
\hline MP2 & $\begin{array}{l}\text { Buccal (mean } \\
\pm S D)(\mathrm{mm})\end{array}$ & $\begin{array}{l}\text { Lingual }(\text { mean } \\
\pm S D)(\mathrm{mm})\end{array}$ & $p$-value \\
\hline PM1 & $0.86 \pm 0.76$ & $2.95 \pm 0.96$ & $<0.0001$ \\
PM2 & $0.86 \pm 0.76$ & $1.37 \pm 0.82$ & $<0.0001$ \\
M1M & $1.15 \pm 0.64$ & $2.87 \pm 0.66$ & $<0.0001$ \\
M1D & $1.45 \pm 0.66$ & $3.94 \pm 0.83$ & $<0.0001$ \\
M2M & $3.05 \pm 1.67$ & $3.36 \pm 1.08$ & 0.5289 \\
M2D & $3.63 \pm 1.96$ & $3.84 \pm 1.20$ & 0.7234 \\
\hline
\end{tabular}

SD: Standard deviation

Table 6: Frequency distribution of teeth according to thickness of buccal and lingual walls (percentage)

\begin{tabular}{|c|c|c|c|c|c|c|}
\hline & \multicolumn{2}{|c|}{$<1 \mathrm{~mm}$} & \multicolumn{2}{|c|}{$1-2 \mathrm{~mm}$} & \multicolumn{2}{|c|}{$>2 \mathrm{~mm}$} \\
\hline & Buccal & Lingual & Buccal & Lingual & Buccal & Lingual \\
\hline \multicolumn{7}{|l|}{ MP1 } \\
\hline PM1 & 88.23 & 29.41 & 11.76 & 41.17 & 0 & 29.41 \\
\hline PM2 & 88.89 & 11.11 & 11.11 & 50 & 0 & 38.89 \\
\hline M1M & 64.28 & 14.28 & 28.57 & 35.71 & 7.14 & 50 \\
\hline M1D & 57.14 & 0 & 42.86 & 35.71 & 0 & 64.29 \\
\hline M2M & 31.25 & 6.25 & 43.75 & 62.50 & 25 & 31.25 \\
\hline M2D & 37.50 & 0 & 25 & 31.25 & 37.50 & 68.75 \\
\hline \multicolumn{7}{|l|}{ MP2 } \\
\hline PM1 & 64.70 & 0 & 29.41 & 23.52 & 5.88 & 76.47 \\
\hline PM2 & 33.33 & 5.55 & 50 & 5.55 & 16.67 & 88.89 \\
\hline M1M & 42.86 & 0 & 42.86 & 14.29 & 14.29 & 85.71 \\
\hline M1D & 28.57 & 0 & 50 & 0 & 21.43 & 100 \\
\hline M2M & 18.75 & 0 & 6.25 & 6.25 & 75 & 93.75 \\
\hline M2D & 0 & 0 & 25 & 0 & 75 & 100 \\
\hline
\end{tabular}

and BW2 was measured $(\mathrm{H})$, which shows distance of inferior alveolar bony canal from alveolar crest.

\section{DISCUSSION}

Recently, efforts have been taken to decrease overall treatment time and surgical interventions in implant therapy. 


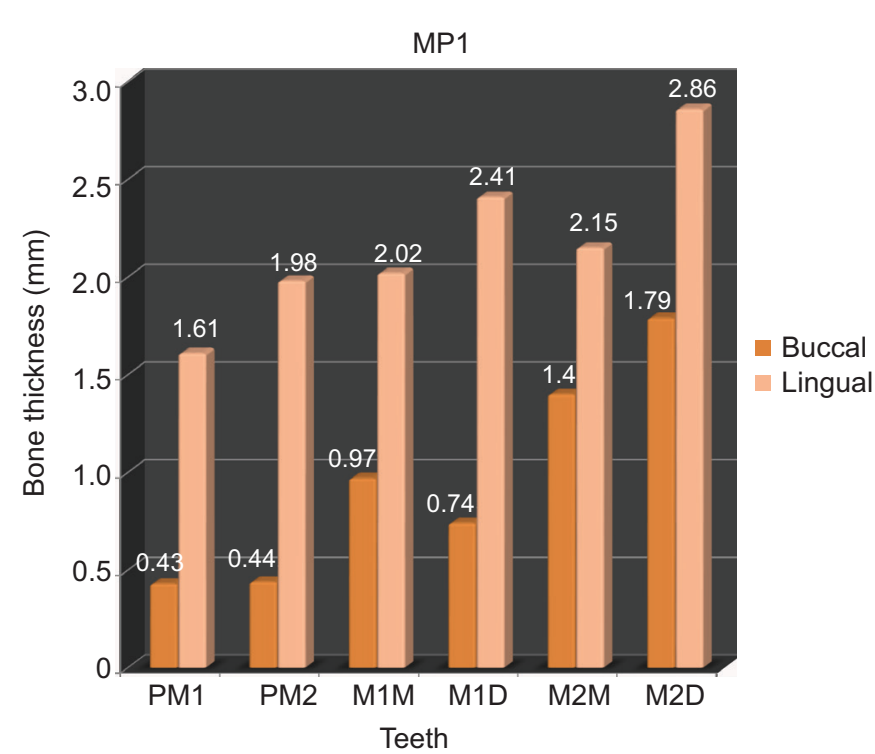

Graph 1: Thickness of buccal and lingual bone walls at MP1

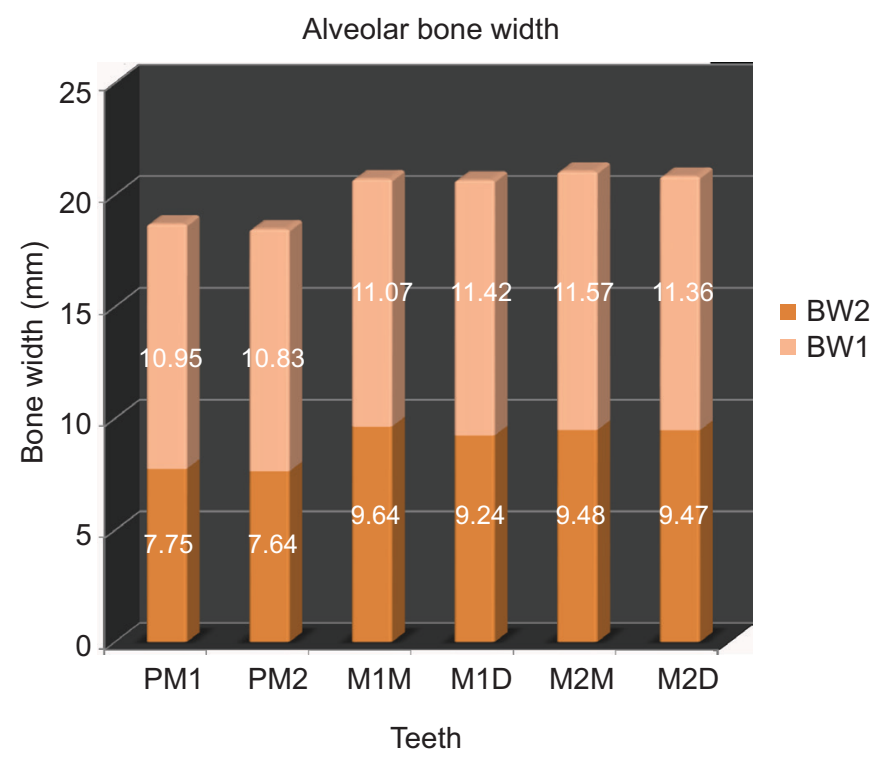

Graph 3: Bone width at BW1 and BW2

Table 7: Alveolar bone width of mandibular posterior teeth

\begin{tabular}{lllll}
\hline & $\begin{array}{l}\text { Minimum } \\
(\mathrm{mm})\end{array}$ & $\begin{array}{l}\text { Median } \\
(\mathrm{mm})\end{array}$ & $\begin{array}{l}\text { Maximum } \\
(\mathrm{mm})\end{array}$ & $\begin{array}{l}\text { Mean } \\
(\mathrm{mm})\end{array}$ \\
\hline BW1 & & & & \\
PM1 & 5.47 & 7.53 & 10.75 & 7.752 \\
PM2 & 6.66 & 7.57 & 9.32 & 7.641 \\
M1M & 7.95 & 9.54 & 11.15 & 9.635 \\
M1D & 7.56 & 9.295 & 10.92 & 9.242 \\
M2M & 7.71 & 9.285 & 11.39 & 9.476 \\
M2D & 6.59 & 9.53 & 12.5 & 9.468 \\
BW2 & & & & \\
PM1 & 7.96 & 10.83 & 13.75 & 10.948 \\
PM2 & 7.06 & 10.91 & 15.48 & 10.830 \\
M1M & 9.04 & 11.105 & 15.11 & 11.072 \\
M1D & 8.86 & 10.675 & 15.73 & 11.416 \\
M2M & 8.67 & 11.295 & 17.54 & 11.573 \\
M2D & 7.55 & 11.115 & 15.39 & 11.356 \\
\hline
\end{tabular}

BW1: bone width at most coronally detectable alveolar bone, BW2: bone width at the superior border of inferior alveolar canal

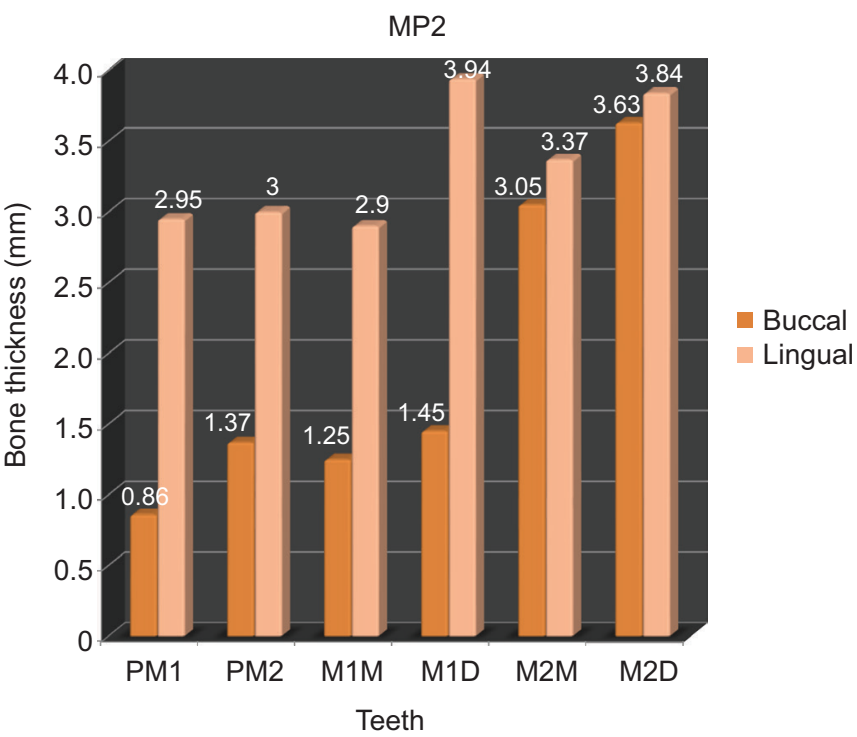

Graph 2: Thickness of buccal and lingual bone wall thickness at MP2

Table 8: Dimensions of BW1 and BW2 for all teeth $(p<0.05$ significant $)$

\begin{tabular}{llll}
\hline Column1 & $\begin{array}{l}B W 1(\text { mean } \pm \\
S D)(\mathrm{mm})\end{array}$ & $\begin{array}{l}B W 2(\text { mean } \pm \\
S D)(\mathrm{mm})\end{array}$ & $p$-value \\
\hline PM1 & $7.75 \pm 1.16$ & $10.95 \pm 1.93$ & $<0.0001$ \\
PM2 & $7.64 \pm 0.76$ & $10.83 \pm 1.87$ & $<0.0001$ \\
M1M & $9.64 \pm 0.78$ & $11.87 \pm 1.07$ & 0.0133 \\
M1D & $9.24 \pm 0.88$ & $11.42 \pm 2.01$ & 0.001 \\
M2M & $9.48 \pm 1.03$ & $11.57 \pm 2.33$ & 0.0026 \\
M2D & $9.47 \pm 1.5$ & $11.36+2.36$ & 0.0112 \\
\hline
\end{tabular}

Alternative to conventional approach, immediate or early implant placement approaches have been proposed. ${ }^{6}$ According to the survey of Swiss dental practitioners in 1994, most frequent indications for implant therapy were found to be completely edentulous mandible followed by edentulous posterior mandible. ${ }^{78}$ Hence, analysis of bone dimensions in posterior mandible for implant placement is important.

Esthetic implant prosthesis, according to Belser et al, ${ }^{9}$ was defined as the one that is in harmony with perioral facial structures of the patient. Tomasi et $\mathrm{al}^{3}$ stated that the thickness of the buccal bone wall is a key determinant of implant treatment success following extraction. The thickness of the buccal bone wall is associated with the degree of defect fill following implant placement. ${ }^{3}$ Importance of analysis of bone dimensions before future implant placement is well documented in the literature.

Current trend in implant therapy is shifting from conventional implant therapy to immediate implant therapy. According to Huynh-Ba et $\mathrm{al}_{1}^{10}$ placement of immediate implant may preserve bone dimensions. Analysis of bone dimensions is a must before immediate implant placement to determine the need of bone augmentation and appropriate treatment planning. 
Inadequate amount of remaining bone following implant therapy can cause treatment failure. Following extraction, bony alterations are most commonly seen in the coronal portion of the alveolar ridge. Therefore, measurements of mandibular posterior teeth at MP1 are of utmost importance. ${ }^{1}$ In the present study, it was evident that buccal bone dimensions at MP1 for majority of teeth were less than $1 \mathrm{~mm}$. This was observed more in premolars than molars. According to Braut et al, ${ }_{11}^{11}$ after implant bed preparation, the buccal bone wall should measure at least $2 \mathrm{~mm}$ in thickness. This thickness is necessary for maintaining proper soft tissue support and to avoid bone resorption following restoration..$^{11}$ Spray et al ${ }^{12}$ concluded that bone loss decreased significantly as bone thickness was approximately $2 \mathrm{~mm}$. According to Grunder et al, ${ }_{13}^{13}$ bone thickness should preferably be $4 \mathrm{~mm}$. If this thickness of bone is not available, then resorption on buccal bone is likely to occur that may cause gingival recession. Analysis showed an increase in thickness of bone from premolars to molars owing to lingual inclination of molars that results in thicker alveolar bone walls.

Vertical distance between BW1 and BW2 was alveolar height $(\mathrm{H})$. This $\mathrm{H}$ value is of clinical significance, as immediate implants should be placed within this height. Violation of this vertical distance can traumatize inferior alveolar nerve that can lead to implant failure. According to Watanabe et al, ${ }_{1}^{14}$ prevalence of lingual undercut above inferior alveolar canal was found to be 36 to $39 \%$. Although the implant axis in the mandible should ideally point toward the palatal cusp of the opposing tooth, a lingual undercut increases the risk of lingual perforation and surgical complications. To avoid this anatomical landmark, an implant could be placed off-axially and would have to be restored with an angled abutment.1,15

Findings of this study were consistent with those of Braut et al. ${ }^{1}$ This study comprised all the patients who were selected for implant placement. Analysis of bone dimensions was done keeping in mind immediate implant therapy if needed in future. Also, this study assesses the prevalence of inadequate bone dimensions at mandibular posterior teeth.

\section{CONCLUSION}

Careful preoperative analysis using CBCT is useful in the assessment of thin or missing bone walls and thus determining the need for bone augmentation procedure. Owing to broader alveolar bone and adequate bone thickness, prognosis of implants placed in the molar region is better than that of premolars.

\section{CLNICAL SIGNIFICANCE}

To achieve long-lasting and ideal results with the implants, minimum of $2 \mathrm{~mm}$ of buccal bone should be preserved. ${ }^{13}$
Inadequate bone may result in implant failure. To prevent this, bone augmentation procedures are required. Currently, there is insufficient data regarding preoperative bone dimension analysis of mandibular posterior teeth. As CBCT is the preferred imaging modality for oral and maxillofacial structures, careful preoperative analysis of alveolar bone dimensions may determine the need for bone augmentation. Thus, it will significantly increase the success rate of immediate implant treatment in the mandibular posterior teeth. ${ }^{1}$

\section{REFERENCES}

1. Braut $\mathrm{V}$, Bornstein $\mathrm{M}$, Lauber R, Buser D. Bone dimensions in the posterior mandible: a retrospective radiographic study using cone beam computed tomography. Part 1-analysis of dentate sites. Int J Periodontics Restorative Dent 2012 Apr;32(2):175-184.

2. Schropp L, Wenzel A, Kostopoulos L, Karring T. Bone healing and soft tissue contour changes following single-tooth extraction: a clinical and radiographic 12-month prospective study. Int J Periodontics Restorative Dent 2003 Aug;23(4): 313-323.

3. Tomasi C,SanzM,Cecchinato D, Pjetursson B, Ferrus J, Lang NP, Lindhe J. Bone dimensional variations at implants placed in fresh extraction sockets: a multilevel multivariate analysis. Clin Oral Impl Res 2010 Jan;21(1):30-36.

4. Loubele M, Van Assche N, Carpentier K, Maes F, Jacob R, Van Steenberghe D, Suetens P. Comparative localized linear accuracy of small-field cone-beam CT and multislice CT for alveolar bone measurements. Oral Surg Oral Med Oral Pathol Oral Radiol Endod 2008 Apr;105(4):512-518.

5. Van Steenberghe D, Naert I, Andersson M, Brajnovic I, Van Cleynenbreugel J, Suetens P. A custom template and definitive prosthesis allowing immediate implant loading in the maxilla: a clinical report. Int J Oral Maxillofac Implants 2002 Sep-Oct;17(5):663-670.

6. Buser D, Chen ST, Weber HP, Belser UC. Early implant placement following single-tooth extraction in the esthetic zone: biologic rationale and surgical procedures. Int J Periodontics Restorative Dent 2008 Oct;28(5):441-451.

7. Lambrecht JT, Besimo CE, Guindy JS. The determination of the status of dental implantology in Switzerland. Schweiz Monatsschr Zahnmed 1999;109(1):18-30.

8. Bornstein MM, Halbritter S, Harnisch H, Weber HP, Buser D. A retrospective analysis of patients referred for implant placement to a specialty clinic: indications, surgical procedures, and early failures. Int J Oral Maxillofac Implants 2008 Nov-Dec;23(6):1109-1116.

9. Belser U, Buser D, Higginbottom F. Consensus statements and recommended clinical procedures regarding esthetics in implant dentistry. Int J Oral Maxillofac Implants 2004;19 (Suppl):73-74.

10. Huynh-Ba G, Pjetursson BE, Sanz M, Cecchinato D, Ferrus J, Lindhe J, Lang NP. Analysis of socket bone wall dimensions in the upper maxilla in relation to immediate implant placement. Clin Oral Implants Res 2010 Jan;21(1):37-42.

11. Braut V, Bornstein MM, Belser U, Buser D. Thickness of the anterior maxillary facial bone wall-a retrospective radiographic study using cone beam computed 
tomography. Int J Periodontics Restorative Dent 2011 Apr; 31(2):125-131.

12. Spray JR, Black CG, Morris HF, Ochi S. The influence of bone thickness on facial marginal bone response: stage 1 placement through stage 2 uncovering. Ann Periodontol 2000 Dec;5(1):119-128.

13. Grunder U, Gracis S, Capelli M. Influence of the 3D boneto-implant relationship on esthetics. Int J Periodontics Restorative Dent 2005 Apr;25(2):113-119.
14. Watanabe $\mathrm{H}$, Mohammad Abdul M, Kurabayashi T, Aoki H. Mandible size and morphology determined with CT on a premise of dental implant operation. Surg Radiol Anat 2010 Apr;32(4):343-349.

15. Chan HL, Benavides E, Yeh CY, Fu JH, Rudek IE, Wang HL. Risk assessment of lingual plate perforation in posterior mandibular region: a virtual implant placement study using cone-beam computed tomography. J Periodontol 2011 Jan;82(1):129-135. 